University of Nebraska - Lincoln

DigitalCommons@University of Nebraska - Lincoln

2010

The Past, Present, and Future of Comparative Effectiveness

Research in the US Department of Veterans Affairs

Joel Kupersmith

US Department of Veterans Affairs

Alexander K. Ommaya

US Department of Veterans Affairs

Follow this and additional works at: https://digitalcommons.unl.edu/publichealthresources

Part of the Public Health Commons

Kupersmith, Joel and Ommaya, Alexander K., "The Past, Present, and Future of Comparative Effectiveness Research in the US Department of Veterans Affairs" (2010). Public Health Resources. 180.

https://digitalcommons.unl.edu/publichealthresources/180

This Article is brought to you for free and open access by the Public Health Resources at DigitalCommons@University of Nebraska - Lincoln. It has been accepted for inclusion in Public Health Resources by an authorized administrator of DigitalCommons@University of Nebraska - Lincoln. 


\title{
The Past, Present, and Future of Comparative
} Effectiveness Research in the US Department of Veterans Affairs

\author{
Joel Kupersmith, MD, Alexander K. Ommaya, ScD, MA \\ Office of Research and Development, US Department of Veterans Affairs, Washington, District of Columbia, USA.
}

\begin{abstract}
A particular challenge for the healthcare provider and the patient is to choose among competing therapeutic approaches for a particular condition. Often, the relative benefits and risks of potential therapies are not uniformly available from the existing scientific information. Many have pointed to the need for more comparative effectiveness research (CER) to aide in these decisions. The US Department of Veterans Affairs (VA) has a long history of conducting CER. The success of the VA CER program has been facilitated by several important aspects of scientific infrastructure related to (1) research question refinement, (2) study design, planning and coordination, (3) evidence synthesis, and (4) implementation research. In publications that had VA coauthors in 2 major medical journals, $25 \%$ of the published studies were classified as CER. The most frequent categories of study were pharmaceutical and behavioral interventions. In the future, the CER enterprise will move toward increased input from clinicians in research topic choice and enhanced consideration of other methodologies besides the randomized controlled trial.
\end{abstract}

(C) 2010 Published by Elsevier Inc. • The American Journal of Medicine (2010) 123, e3-e7

KEYWORDS: Clinical trials; Comparative effectiveness research; Observational research; Veterans affairs

A well-recognized challenge in the US healthcare system is the consistent use of evidence in medical decision making. ${ }^{1,2}$ A particular challenge for the healthcare provider and the patient is to choose among competing therapeutic approaches for a particular condition, e.g., choice of a particular drug for depression. Often, the relative benefits and risks of potential therapies are not uniformly available from the existing scientific information, a situation sometimes referred to as the "inferential gap." "3,4

The availability of scientific information regarding effectiveness is more limited than information regarding efficacy, in part because studies designed for regulatory approval do not mirror "real-world" practice. ${ }^{5}$ However,

Statement of author disclosure: Please see the Author Disclosures section at the end of this article.

The views, opinions, and content in this article are those of the author and do not necessarily reflect the views, opinions, or policies of the US Department of Veterans Affairs.

Requests for reprints should be addressed to Joel Kupersmith, MD, US Department of Veterans Affairs, Office of Research and Development (12), 810 Vermont Avenue NW, Washington, District of Columbia 20420.

E-mail address: Joel.Kupersmith@va.gov. efficacy data may also be limited, depending on the type of intervention (drugs, medical devices, or surgical procedures), and the time that the intervention has been available and its degree of use. In addition, treatments that have demonstrated efficacy will not work for all patients. For some they may be ineffective or harmful, e.g., patients with comorbidities or different genetic compositions. For physicians and patients a key treatment question is often which of the several alternative treatments should be considered. Efficacy trials, randomized controlled trials (RCTs), usually exclude patients with comorbidities and therefore do not provide direct evidence relevant to the most challenging patient groups for healthcare providers to manage. RCTs are also often designed with intermediate measures as endpoints, and thus do not provide the information most desired by physicians, patients, and other medical decision makers. Additionally, short follow-up times do not allow appreciation of survival or longer-term outcome measures. The 2007 report from the Medicare Payment Advisory Commission concluded that there is not enough empirically based information for healthcare providers and patients to make informed treatment decisions. ${ }^{6}$ The commission also noted 
that variations in care are high when evidence is unclear. Comparative research is most often available for cardiovascular and endocrine conditions and least available for neurologic and pulmonary conditions. ${ }^{7}$

There are several significant study design challenges in conducting comparative effectiveness research (CER) in general. In placebo-controlled trials a treatment is evaluated in comparison to an inert treatment. In active-controlled trials there is comparison of equivalence or noninferiority with a prespecified amount of a comparator and a treatment with known efficacy. ${ }^{8}$

The most robust design in an active-controlled study is inclusion of a placebo group in a 3-arm design (when there is equipoise for this arm and therefore ethical acceptability). This design allows for direct demonstration of superiority in reference to the placebo. ${ }^{9}$

For active-controlled trials, a new treatment should be compared with standard treatment when there is sufficient evidence such that it can serve as a reference treatment. The reference treatment should have a well-established predictable effect at the dose and protocol to be tested. Intensity of treatment and dose should be equipotent. The dose regimens also should be comparable, and trial endpoints should not favor a particular intervention.

It is important to guard against bias in comparative studies, especially when methods other than RCTs are used. Studies that rely only on administrative data may classify cases inappropriately owing to missing information or may lack information regarding relevant factors or exposures (i.e., information or selection bias). Lack of data on potential confounders (i.e., factors that are associated with treatment and outcome) may also be an issue. Uses of methods such as propensity scores and instrumental variables have been described as approaches that can mimic randomization. ${ }^{10,11}$ Propensity scores are a quasi-experimental correction strategy in which a predicted probability of group membership (control or experimental) is derived and may also be used for matching, or as a covariate. ${ }^{12}$ Another quasi-experimental method is use of instrumental variables. ${ }^{13}$ An instrumental variable is a variable that is correlated with the treatment and is related to the outcome only through the association with treatment. Further descriptions of these techniques are discussed by Concato and cowork$\mathrm{ers}^{14}$ elsewhere in this supplement. Regardless of the analysis approach used, the primary focus should be on reducing sources of bias (e.g., multiple exposure bias) and adjusting for confounding (e.g., adherence differences), rather than hoping for a "magic bullet" provided by the methodological approach. ${ }^{15}$ At times, groups of studies with varying methodologies and approaches to patient follow-up may be appropriate.

The conduct of CER requires appropriate infrastructure for successful completion of studies. The Federal Coordinating Council for CER research outlined infrastructure needs for this research (Table 1). Depending on the question and approach of the study various capabilities identified in Table 1 will be required. The US Department of Veterans Affairs (VA) has all of the aspects of the scientific infra-
Table 1 Comparative Effectiveness Research Scientific Infrastructure

a. Administrative databases

b. EHRs and distributed data networks

c. Clinical research networks

d. Registries, surveillance databases, research-quality observational datasets

e. Tools for dissemination and translation of research findings f. Human and scientific capital

Table 2 Veterans Health Administration (FY2009)

- Total enrollees in the VA healthcare system: $8.06 \mathrm{M}$

- Total unique patients treated:

- Number of VA medical centers:

- Number of community-based outpatient clinics:

788

- Number of VA Vet Centers*:

232

VA $=$ US Department of Veterans Affairs.

*Vet Centers provide readjustment counseling, outreach, and referral services.

structure outlined in Table 1. The VA is one of the largest organized health systems and has the largest medical education and health professions training programs in the United States. ${ }^{16}$ The VA's medical facilities are affiliated with 107 medical schools, 55 dental schools, and >1,200 other schools. Roughly 90,000 health professionals are trained in the VA each year. The number of patients treated and medical facilities included in the Veterans Health System are indicated in Table 2. The VA electronic health record is available at all sites of care.

CER with the greatest impact addresses questions that focus on gaps in existing evidence, and, when completed, provides timely information for medical decision making. ${ }^{17}$ The goal of the research is to facilitate the best use of medical interventions or technologies, i.e., identifying which types of patients would most benefit from particular treatments. An Institute of Medicine (IOM) workshop held in 2001 highlighted the current deficiency and need for effectiveness research. ${ }^{18}$ Following this workshop, members of the IOM Clinical Research Roundtable published recommendations regarding a definition of effectiveness research and mechanisms for research question formulation. ${ }^{19}$ More recently, CER has received more attention, and a Patient-Centered Research Institute focusing on supporting CER was established as part of Public Law No: 111-148. SEC 6301, 2010.

The VA CER research program is unique because it is embedded within a national health system. The VA has the resources and infrastructure (including electronic health records, clinical research pharmacy, etc.) to fully support and execute CER research, including large multicenter clinical trials. Additionally, roughly $70 \%$ of VA researchers are also clinicians, exposing them to clinically relevant issues. The VA Cooperative Studies Program (CSP) provides a 
Table 3 Distribution of US Department of Veterans Affairs (VA) Comparative Effectiveness Research (CER) studies published in 2 major medical journals over a 3-year period*

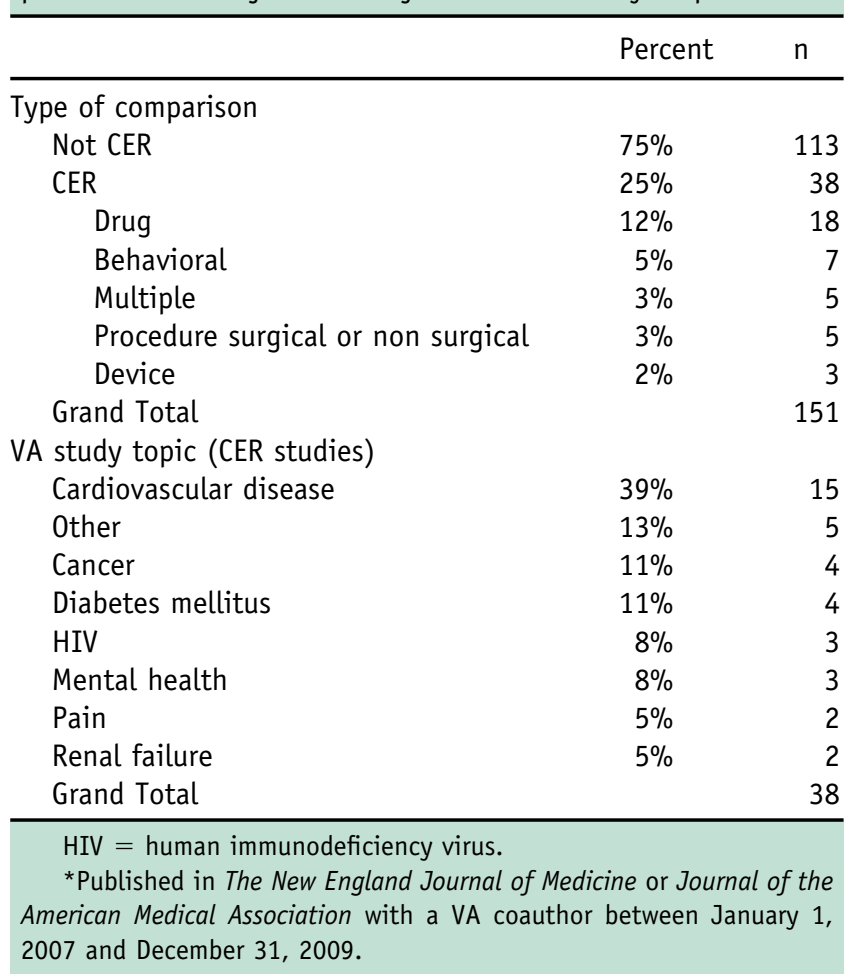

platform to collaboratively identify and refine research questions, many of which are CER. To gather a better understanding of VA CER, we reviewed articles that had VA coauthors published in 2 leading medical journals to determine the proportion of CER, the types of comparisons, and the areas of focus.

\section{METHODS}

Thompson Reuters Science Citation Index Expanded was searched to determine the number of publications in The New England Journal of Medicine (NEJM) and the Journal of the American Medical Association (JAMA) that included VA coauthors. Publications that indicated "Veterans Affairs," "Veterans Medical Center," or "VA healthcare" in the author address fields were selected. The search was conducted on January 20, 2010 and included data from 2007 to 2009. Randomized trials, case-control studies, cohort studies, and meta-analyses were included in the analyses. Titles and abstracts of articles were reviewed by the coauthors, and were identified as CER using the IOM definition. All studies in which there was a comparison with an active treatment were selected as comparative effectiveness studies. The comparator could involve a usual-care group if the usual care was well defined. All publications identified in the search included VA coauthors $(n=335)$. Letters, editorials, and corrections were excluded from the count $(n=184)$.

\section{RESULTS}

There were 151 articles, reviews, or proceedings papers identified with VA coauthors (Table 3). A total of $25 \%(n=38)$ were identified as CER studies. There was a wide variation in the types of interventions investigated, with pharmaceuticals as the most frequent category. Several studies involved varying types of intervention (e.g., behavior/drug or device/procedure). The distributions of the study topics are identified in Table 3. The most frequent topic was cardiovascular disease. Examples of the identified CER studies are listed in Table $4 .^{20-26}$

\section{DISCUSSION}

The history of CER at the VA extends beyond 30 years. ${ }^{27,28}$ The VA has a dedicated scientific infrastructure for conducting CER that is embedded within the healthcare system. The examples presented in Table 4 indicate the clinical relevance of the CER conducted by VA investigators. In a recent analysis of CER in 6 general medicine journals, the supplementary online content provided a list of articles published in NEJM and JAMA for a 16-month period. Analysis of this list indicated that 26\% (12 of 46) of all the CER articles published in these 2 journals over the 16month period had VA coauthors. Taken together, the data presented here, in addition to the analysis published by Hochman and McCormick, ${ }^{7}$ indicate that the VA, despite its relatively modest research budget, plays a significant role in CER. Despite this effort, as Hochman and McCormick ${ }^{7}$ indicate, there is limited research devoted to assisting physicians in the effective use of therapies. Those unfamiliar with the Veterans Health Administration and VA research often assume that vast majority of research is focused solely on deployment issues. However, as indicated in Table 3, and because of the spectrum of health issues faced by veterans, VA CER focuses on a variety of health issues relevant to the general US population. The mechanism for assuring the clinical relevance of these investigations is 2-fold. First, roughly $70 \%$ of VA investigators are also clinicians; thus, they are directly exposed to clinical needs. Second, the CSP, which supported many of the studies identified in this analysis, begins by identifying questions with high clinical relevance submitted by clinical proponents. ${ }^{29}$ Involving these stakeholders both at the beginning and in consultations with the clinical system throughout the process appears to have benefited the program in terms of the timeliness and clinical relevance of research topics. Other important components are the fixed infrastructure support (e.g., coordinating and methodological centers, peer review) to help ensure the quality of the research. ${ }^{30}$

The connection of the VA health system to VA research allows for the identification and study of important questions that are relevant to the health system but might not be raised by healthcare providers and manufacturers with financial interests in the technology or procedure. An example of a recent CER study is the Clinical Outcomes Utilizing Revascularization and Aggressive Drug Evaluation (COURAGE) trial, which showed that the majority of 
Table 4 Examples of Comparative Effectiveness Research Publications that Include US Department of Veterans Affairs (VA) co-authors Published in The New England Journal of Medicine and Journal of the American Medical Association

\begin{tabular}{|c|c|c|}
\hline Title & Comparison & Results \\
\hline $\begin{array}{l}\text { On-Pump versus 0ff-Pump Coronary-Artery } \\
\text { Bypass Surgery }\end{array}$ & On Pump vs. off Pump & $\begin{array}{l}\text { The off-pump group had worse composite outcomes } \\
\text { and poorer graft patency than patients in the on- } \\
\text { pump group }\end{array}$ \\
\hline $\begin{array}{l}\text { Risk of Adverse Outcomes Associated with } \\
\text { Concomitant Use of Clopidogrel and } \\
\text { Proton Pump Inhibitors Following Acute } \\
\text { Coronary Syndrome }\end{array}$ & $\begin{array}{l}\text { Clopidogrel with or without a } \\
\text { PPI }\end{array}$ & $\begin{array}{l}\text { Increased risk of adverse outcomes was associated } \\
\text { with use of clopidogrel and PPI after hospital } \\
\text { discharge for ACS }\end{array}$ \\
\hline $\begin{array}{l}\text { Outcomes Following Endovascular vs. } \\
\text { Open Repair of Abdominal Aortic } \\
\text { Aneurysm: A Randomized Trial }{ }^{25}\end{array}$ & $\begin{array}{l}\text { Endovascular vs. open repair of } \\
\text { abdominal aortic aneurysm }\end{array}$ & $\begin{array}{l}\text { Perioperative mortality was reduced for endovascular } \\
\text { repair at } 30 \text { days, but there was no difference in } \\
\text { mortality at } 2 \mathrm{yr}\end{array}$ \\
\hline $\begin{array}{l}\text { Optimal medical therapy with or without } \\
\text { PCI for stable coronary disease }{ }^{26}\end{array}$ & $\begin{array}{l}\text { Optimal medical therapy vs. } \\
\text { percutaneous coronary } \\
\text { intervention }\end{array}$ & $\begin{array}{l}\text { The PCI group and medical-therapy group were } \\
\text { comparable in the composite index of death, } \\
\text { myocardial infarction, and stroke; hospitalization } \\
\text { for ACS; or myocardial infarction }\end{array}$ \\
\hline
\end{tabular}

$\mathrm{ACS}=$ acute coronary syndromes; CBT = cognitive behavioral therapy; EUC = Enhanced usual care; PPI = proton pump inhibitor.

patients with optimal medical therapy had substantial improvements in health status for $>4$ years. ${ }^{26}$ The COURAGE findings are most applicable to patients with chronic stable chest pain. The implication for clinical practice is that use of percutaneous coronary intervention first should probably not be adopted for patients with stable angina. In the month following the publication of the article, US stent implants declined by $13 \%$, but by 2009 the number of implants returned to previous levels. ${ }^{31}$ These data point to the challenges in translating research into healthcare practice and in sustaining behavioral change. Evidence-based medical guidelines (EBM), based on empirical research, have been developed for many of the conditions identified in the IOM report Crossing the Quality Chasm: A New Health System for the 21st Century. ${ }^{32}$ Yet, health services researchers and others have found that physicians and other healthcare providers frequently do not follow such guidelines. ${ }^{33-35}$ Some of the obstacles to implementing EBM include the amount and complexity of research; limitations on clinicians' time; policies that do not encourage use of EBM; organizational barriers; lack of incentives to participate in educational activities; experiences, beliefs, and attitudes of healthcare providers that contradict EBM findings; local differences in healthcare delivery; and patient experience, beliefs, and attitudes that affect adherence. ${ }^{36,37}$ Variations in individual patients may also limit implementation of EBM. ${ }^{38}$ The
Quality Enhancement Research Initiative (QUERI) is focused directly on this implementation problem in the VA. ${ }^{39}$

In the future, CER will be a much more prominent part of the research enterprise and it, in turn, will have many influences on both the research and clinical enterprises. The interest and movement toward CER will influence how research projects are identified and chosen, with more input from clinicians and the healthcare system as in the VA CSP. Also, recognition of the need for research efficiency will move the field beyond the RCT to other methodologies described above, though hopefully with great care.

Finally, CER will provide the information necessary to better inform choices for patients, providers, and the healthcare system. The choices will not only rely on CER, as it is currently considered, but on a complex of interacting and coalescing research vehicles. CER will be one such vehicle and personalized medicine, to address the issue of individual differences in response, another. Out of the synthesis will come vast improvement in our approach to the health of veterans and everyone else.

Joel Kupersmith, MD, has no financial arrangement or affiliation with a corporate organization or manufacturer of a product discussed in this article. 
Alexander K. Ommaya, ScD, MA, has no financial arrangement or affiliation with a corporate organization or manufacturer of a product discussed in this article.

\section{References}

1. Shrank WH, Asch SM, Adams J, et al. The quality of pharmacologic care for adults in the United States. Med Care. 2006;44:936-945.

2. Asch SM, Kerr EA, Keesey J, et al. Who is at greatest risk for receiving poor-quality health care? N Engl J Med. 2006;354:11471156.

3. Tunis SR, Stryer DB, Clancy CM. Practical clinical trials: increasing the value of clinical research for decision making in clinical and health policy. JAMA. 2003;290:1624-1632.

4. Perlin JB, Kupersmith J. Information technology and the inferential gap. Health Aff (Millwood). 2007;26:w192-w194.

5. Wang PS, Ulbricht CM, Schoenbaum M. Improving mental health treatments through comparative effectiveness research. Health Aff (Millwood). 2009;28:783-791.

6. Medicare Payment Advisory Commission. Report to congress: promoting greater efficiency in Medicare. Washington, DC: Medicare Payment Advisory Commission (MedPAC), June 2007.

7. Hochman M, McCormick D. Characteristics of published comparative effectiveness studies of medications. JAMA. 2010;303:951-958.

8. Siqueira AL, Whitehead A, Todd S. Active-control trials with binary data: a comparison of methods for testing superiority or non-inferiority using the odds ratio. Stat Med. 2008;27:353-370.

9. European Medicines Agency, Committee for Medicinal Products for Human Use (CHMP). Guideline on the choice of the non-inferiority margin. Doc. Ref. EMEA/CPMP/EWP/2158/99. Available at: http:// www.ema.europa.eu/pdfs/human/ewp/215899en.pdf. Accessed March $18,2010$.

10. Everhart JE, Lombardero M, Detre KM, et al. Increased waiting time for liver transplantation results in higher mortality. Transplantation. 1997;64:1300-1306.

11. Shah BR, Hux JE, Laupacis A, Zinman B, van Walraven C. Clinical inertia in response to inadequate glycemic control: do specialists differ from primary care physicians? Diabetes Care. 2005;28:600-606.

12. Rosenbaum PR, Rubin DB. The central role of the propensity score in observational studies for causal effects. Biometrika. 1983;70:41-55.

13. Newhouse JP, McClellan M. Econometrics in outcomes research: the use of instrumental variables. Annu Rev Public Health. 1998;19:17-34.

14. Concato J, Lawler EV, Lew RA, Gaziano JM, Aslan M, Huang GD. Observational methods in comparative effectiveness research. Am J Med. 2010;123[suppl]:e16-e23.

15. Johnson ML, Crown W, Martin BC, Dormuth CR, Siebert U. Good research practices for comparative effectiveness research: analytic methods to improve causal inference from nonrandomized studies of treatment effects using secondary data sources: the ISPOR Good Research Practices for Retrospective Database Analysis Task Force Report-Part III. Value Health. 2009;12:1062-1073.

16. US Department of Veterans Affairs. Fact Sheet: Facts About the Department of Veterans Affairs. Available at: http://www1.va.gov/ opa/fact/vafacts.asp. Accessed March 19, 2010.

17. Gibbons RJ, Gardner TJ, Anderson JL, et al. for the American Heart Association Advocacy Coordinating Committee. The American Heart Association's principles for comparative effectiveness research: a policy statement from the American Heart Association. Circulation. 2009; 119:2955-2962.

18. Tunis S, Korn A, Ommaya A (eds). The Role of Purchasers and Payers in the Clinical Research Enterprise: Workshop Summary. Washington, DC: National Academies Press, 2002.

19. Kupersmith J, Sung N, Genel M, et al. Creating a new structure for research on health care effectiveness. J Investig Med. 2005;53:67-72.
20. Stanley MA, Wilson NL, Novy DM, et al. Cognitive behavior therapy for generalized anxiety disorder among older adults in primary care: a randomized clinical trial. JAMA. 2009;301:1460-1467.

21. Shroyer AL, Grover FL, Hattler B, et al. for the Veterans Affairs Randomized On/Off Bypass (ROOBY) Study Group. On-pump versus off-pump coronary-artery bypass surgery. N Engl J Med. 2009;361: 1827-1837.

22. Weaver FM, Follett K, Stern M, et al. for the CSP 468 Study Group. Bilateral deep brain stimulation vs best medical therapy for patients with advanced Parkinson disease: a randomized controlled trial. JAMA. 2009;301:63-73.

23. Ho PM, Maddox TM, Wang L, et al. Risk of adverse outcomes associated with concomitant use of clopidogrel and proton pump inhibitors following acute coronary syndrome. JAMA. 2009;301:937944.

24. Duckworth W, Abraira C, Moritz T, et al. for the VADT Investigators. Glucose control and vascular complications in veterans with type 2 diabetes. N Engl J Med. 2009;360:129-139.

25. Lederle FA, Freischlag JA, Kyriakides TC, et al. for the Open Versus Endovascular Repair (OVER) Veterans Affairs Cooperative Study Group. Outcomes following endovascular vs open repair of abdominal aortic aneurysm: a randomized trial. JAMA. 2009;302:1535-1542.

26. Boden WE, O'Rourke RA, Teo KK, et al. for the COURAGE Trial Research Group. Optimal medical therapy with or without PCI for stable coronary disease. N Engl J Med. 2007;356:1503-1516.

27. Read RC, Murphy ML, Hultgren HN, Takaro T. Survival of men treated for chronic stable angina pectoris: a cooperative randomized study. J Thorac Cardiovasc Surg. 1978;75:1-16.

28. Takaro T, Hultgren HN, Lipton MJ, Detre KM. The VA cooperative randomized study of surgery for coronary arterial occlusive disease II: subgroup with significant left main lesions. Circulation. 1976; 54(suppl):III107-III117.

29. Huang GD, Ferguson RE, Peduzzi PN, O'Leary TJ. Scientific and organizational collaboration in comparative effectiveness research: the VA Cooperative Studies Program model. Am J Med. 2010;123[suppl]: e24-e31.

30. VA Cooperative Studies Program. Available at: http://www.research. va.gov/programs/csp/default.cfm. Accessed March 18, 2010.

31. Winstein K. A simple health-care fix fizzles out. Wall Street Journal. February 11, 2010. Available at: http://online.wsj.com/article/ SB10001424052748703652104574652401818092212.html. Accessed March 18, 2010.

32. Institute of Medicine Committee on Quality of Health Care in America. Crossing the Quality Chasm: A New Health System for the 21st Century. Washington, DC: National Academies Press, 2001.

33. Solberg LI, Kottke TE, Brekke ML. Variation in clinical preventive services. Eff Clin Pract. 2001;4:121-126.

34. Haynes RB, Sackett D, Guyatt G, Cook D. Transferring evidence from research to practice: overcoming barriers to application. Evid Based Med. 1997;2:68-69.

35. Cabana MD, Rand CS, Powe NR, et al. Why don't physicians follow clinical practice guidelines? A framework for improvement. JAMA. 1999;282:1458-1465.

36. Haynes B, Haines A. Barriers and bridges to evidence-based clinical practice. BMJ. 1998;317:273-276.

37. Haines A, Donald A. Making better use of research findings. BMJ. $1998 ; 317: 72-75$.

38. Plant N. The human cytochrome P450 sub-family: transcriptional regulation, inter-individual variation and interaction networks. Biochim Biophys Acta. 2007;1770:478-488.

39. Atkins D, Kupersmith J. Implementation research: a critical component of realizing the benefits of comparative effectiveness research. Am J Med. 2010;123[suppl]:e38-e45. 